\title{
ANÁLISE JURÍDICA DA LEGALIDADE DE ATRIBUIÇÃO DE NATUREZA SALARIAL A RENDIMENTOS OBTIDOS A TÍTULO DE DIREITO DE IMAGEM POR PESSOAS JURÍDICAS CONSTITUÍDAS POR ATLETAS PROFISSIONAIS
}

\author{
LEGAL ANALYSIS OF THE LEGALITY OF THE ATTRIBUTION OF \\ SALARY NATURE TO INCOME OBTAINED AS AN IMAGE RIGHT BY \\ LEGAL ENTITIES CONSTITUTED BY PROFESSIONAL ATHLETES
}

\author{
Danilo Henrique Nunes ${ }^{\mathrm{I}}(\mathrm{C})$ \\ Juvêncio Borges Silva ${ }^{\mathrm{II}}$ (i) \\ Fernanda Morato Pereira ${ }^{\mathrm{III}}$ (i)
}

\begin{abstract}
${ }^{\mathrm{I}}$ Universidade de Ribeirão Preto (Unaerp), Ribeirão Preto, SP, Brasil. Doutorando em Direitos Coletivos e Cidadania. E-mail: dhnunes@hotmail.com
\end{abstract}

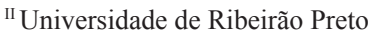
(Unaerp), Docente do Programa de Pós-Graduação em Direitos Coletivos e Cidadania Unaerp, Ribeirão Preto, SP, Brasil. Pósdoutorado em Direito. E-mail: jsilva@unaerp.br

III Universidade de Ribeirão Preto (Unaerp), Ribeirão Preto, SP, Brasil. Mestre Em Direitos Coletivos e Cidadania. E-mail: fernandamorato@live.com

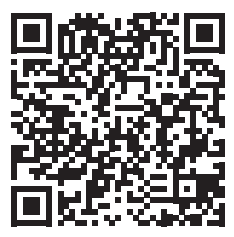

DOI: $10.20912 /$ rdc.v15i36.23

Recebido em: 22.07.2019

Aceito em: 29.02.2020
Resumo: O presente artigo tem como finalidade analisar o direito de imagem dos atletas profissionais e de como são elaborados os contratos, explicitando neles uma proteção para não prejudicar os atletas de futuros danos, demonstrando como declaram um imposto menor em cima desse direito, firmado em contratos profissionais. A diferença dos impostos de pessoas jurídicas e pessoas físicas e a estratégia de pagamento de cada um deles, fazendo com que os atletas profissionais fiquem reféns de seus clubes (pessoa jurídica), são os objetivos do trabalho. O que se pretende, ainda, a partir dos métodos hipotético-dedutivo e de revisão de literatura, é demonstrar como são elaborados estes contratos e quais as formas para burlar o sistema jurídico brasileiro, desviando importantes recursos do Estado, através de alguns salários exorbitantes declarados neles. Assim, o trabalho explica o processo da fiscalização tributária, sejam eles tributos ativos e passivos e, por fim, explica o entendimento jurisprudencial nos casos de fraudes contratuais firmados entre clubes e atleta profissional no momento da sua contratação.

Palavras-chave: Contratos desportivos. Irregularidades contratuais. Direito de imagem.

Abstract: The purpose of this article is to analyze the image rights of professional athletes and how the contracts are drawn up, explaining in them a protection 
not to harm the athletes of future damages, demonstrating how they declare a lower tax on this right, signed in professional contracts. The difference between corporate and individual taxes and the payment strategy of each of them, making professional athletes hostage to their clubs (legal entity), are the objectives of the work. The hypothetico-deductive and literature review methods are also intended to demonstrate how these contracts are elaborated and what are the ways to circumvent the Brazilian legal system, diverting important state resources through some exorbitant salaries declared on them. Thus, the work explains the process of tax inspection, be they active and passive taxes and, finally, explains the jurisprudential understanding in the cases of contractual frauds between clubs and professional athlete at the time of their hiring.

Keywords: Sports contracts. Contractual irregularities. Image rights.

\section{Introdução}

O objetivo deste artigo é verificar e analisar a prática que os clubes desportivos fazem para tributar mediante imposto minorado, dentro do contrato de trabalho dos atletas profissionais, não declarando o real ganho dos mesmos, já que tal situação beneficia ambas as partes, mas prejudica a atividade estatal arrecadatória e, por consequência, a sociedade, que é a destinatária final do bem comum e coletivo promovido pela finalidade da recolhimento dos impostos, taxas e contribuições, nos termos da legislação civil e tributária brasileira.

Assim, os clubes empregadores fazem uso do contrato de licença de uso de imagem que será estudado, neste trabalho, à luz de pesquisa bibliográfica, composta de estudo da legislação brasileira acerca do tema, da doutrina, da jurisprudência e de trabalhos científicos similares para burlar as questões salariais. Nesse sentido, o contrato acaba virando uma espécie de complemento salarial do atleta. 
É indiscutível não falar de esporte que, no mundo, é um fenômeno social, econômico e cultural, além de fomentar o desenvolvimento humano em todas as suas dimensões. Assim, a partir dos métodos hipotético-dedutivo e de revisão de literatura, o que alcançará é que, onde pessoas de todos os estilos, religiões, comportamentos e costumes celebrarem relações jurídicas no âmbito dos esportes, precisam atender à legalidade. Por isso, é preciso, também, adentrarmos em relevante aspecto e, de certa maneira polêmico, na vida profissional dos atletas, qual seja, o de questões jurídicas desta legalidade de atribuição de natureza salarial a rendimentos obtidos a título de direito de imagem por pessoas jurídicas constituídas por atletas profissionais. $\mathrm{O}$ maior foco, ainda, é mostrar a principal estratégia da maioria dos clubes, nos quais possuem atletas com salários exorbitantes e a intenção de alguns clubes fazem para não terem uma aplicação alta dos tributos em cima desses enormes salários que deveriam ser declarados ao todo.

As relações contratuais na indústria do entretenimento sofrem mudanças singulares e significativas contemporaneamente, não só pelas tecnologias de informação e de comunicação, mas, principalmente, em razão da segurança jurídica de ambas as partes que as celebram, atingindo, na perspectiva da personalidade, até mesmo, a moralidade. A exemplo, as cláusulas de moralidade, que se aplicam no direito civil e contratual - no âmbito público e privado - em países que acreditam em talentos, especialmente nos esportivos. Assim leciona Dirceu Pereira Siqueira e Danilo Henrique Nunes (2018. p. 197):

Estes tipos de cláusulas acabam gerando a possibilidade de rompimento do contrato entre as partes, no caso de ações ou atitudes que maculem a imagem daquela celebridade à qual a empresa, marca ou produto esteja vinculada evitando, desta forma, qualquer associação com um individuo que não goza mais de boa reputação perante a opinião pública.

Por esta razão, o objetivo de análise é relevante pelas partes, no presente trabalho, e se justificam que os títulos de licença de uso de imagem têm caráter civil, sendo assim, deduz-se que os clubes declaram 
uma quantia inferior ao verdadeiro ganho dos atletas, conforme anotação na CTPS (Carteira de Trabalho e Previdência Social), promovendo verdadeiro desvirtuamento desta relação, qual seja, de trabalho, e provocando verdadeira fraude na ordem civilista, deixando de pagar aquilo que, de fato, devem ao erário, a bem da coletividade.

\section{Dos Direitos da Personalidade e do Direito de Imagem}

Analisa-se que são conceitos interligados, pois a personalidade analisa que a pessoa tem seu próprio direito e obrigação. Com essa explicação, ressalta-se o ensinamento de Francisco Cavalcanti Pontes de Miranda (2000, p. 216) que entende "certo, a personalidade em si não é direito; é qualidade, é o ser capaz de direitos, o ser possível estar nas relações jurídicas como sujeito de direito".

Mesmo que o indivíduo não tenha consciência da realidade em que vive, é concedido a ele o direito de personalidade, pelo simples fato de ser pessoa. Tal assunto e direito tem por base o fato de que a personalidade é qualidade própria à condição humana. $\mathrm{O}$ direito da personalidade em todo o mundo é de suma importância, como a proteção a dignidade da pessoa humana, revestida de meta princípio fundamental, por estar inserta no rol do art. $1^{\circ}$, inciso III da CRFB/1988. Assim, oferecem um ponto de apoio a todos os direitos e obrigações do indivíduo. O direito a personalidade também pode ser considerado sob outro aspecto, que a tem como conjunto de características e atributos da pessoa humana, considerada como objeto de proteção por parte do ordenamento jurídico.

\subsection{A Natureza dos Direitos da Personalidade}

Os Direitos da Personalidade, são direitos subjetivos, que têm por objeto os elementos que constituem a personalidade do titular, considerada em seus aspectos físico, moral e intelectual. Com esse entendimento, analisa-se que o direito personalíssimo é aquele que tem atributos físicos, psíquicos e morais da pessoa em si e em suas 
projeções sociais. Nota-se também que os direitos da personalidade possuem valores sobre a vida, a integridade física, honra ou até mesmo a imagem, entre outros valores. Segundo Rubens Limongi França (1988, p.1025), entende-se que "Direitos da personalidade dizem-se as faculdades jurídicas cujo objeto são os diversos aspectos da própria pessoa do sujeito, bem assim da sua projeção essencial no mundo exterior".

Cita-se também a jurista Maria Helena Diniz (2002, p.131), que explica de uma forma mais clara, o que é personalidade: "A personalidade é o conjunto de caracteres próprios da pessoa. É objeto de direito. Para que a pessoa possa ser o que é, para aferir, adquirir e ordenar outros bens".

Aprofundando um pouco mais no tema, analisa-se que existe uma classificação na qual são divididas, por (Direito à vida, Direito geral à liberdade, Direito da integridade física e psíquica, Direito à privacidade, Direito à honra ou no caso direito a reputação, Direito moral do autor e por último Direito à identidade pessoal).

\subsection{Origem histórica do Direito de Imagem}

A Constituição Política no Império do Brasil, podemos dizer que foi inspirado nas Constituição Francesa de 1791 e na Constituição Norte-Americana de 1787, se tratando da proteção a imagem em terras brasileiras, preocupando-se mais com a liberdade em que o indivíduo vivia, pois não concordaram em proteção especifica, à imagem da pessoa.

Como ainda era protegida na órbita judicial, por força de interpretações, até 1934, o direito à imagem, ao contrário do que já se verificava em 1902 no Tribunal de Seine, não integrava o direito posto, sendo que a situação muitas vezes entendida como insegurança do indivíduo, que não tinha como ter uma proteção. Na história constitucional Brasileira, a Constituição de 1934, em virtude do golpe 
de Estado instalado por Getúlio Vargas no ano de 1937, foi por esta Carta que, outorgada pelo "ditador", fundindo as garantias insculpidas nos itens 8 e 16 do art. 113, tornou a intimidade, como tutelada a inviolabilidade do sigilo, neste ponto, a análise anterior. Com a queda de Getúlio Vargas em outubro de 1945, e o fim do Estado Novo, o Brasil, passando por um processo de redemocratização, foi interposto, em 18 de setembro de 1946, com uma nova Constituição.

Observa-se que nas Constituições revogadas, o direito de imagem vem sempre apoiado em uma forma oculta por outros direitos de personalidade como descrito no tópico anterior, como é o caso, da intimidade, da honra. Somente a Carta Magna de 1988 trouxe uma proteção no texto constitucional. Com o surgimento da fotografia e da tecnologia, o avanço em como as imagens se espalham em uma forma dinâmica, ficando mais fácil em divulgar, registrar, compartilhar a imagem da pessoa, trazendo com ela a fisionomia, a cultura, os costumes e os momentos históricos. Deste modo, Orlando Gomes (2007, p. 140) menciona:

Foi no século $\mathrm{XX}$ que começaram a acontecer as primeiras exposições públicas da imagem dos indivíduos comuns. A consequência desse importante avanço técnico é a exploração indevida da imagem alheia. Nesse sentido, conforme a propagação da imagem pessoal se alastrava, as sociedades sentiram a necessidade de tutelar a proteção à imagem, já que o coletivo passou a interferir na esfera privada dos indivíduos.

No Brasil, a preocupação com a imagem de forma mais clara, demorou a aparecer. A Constituição Federal de 1988 inaugura uma nova maneira de tratar esse assunto, dentro dos direitos da personalidade e, portanto, garantindo a autonomia necessária aos dias de hoje, dá-se a este fenômeno, o nome de constitucionalização de direitos, incluindose, os direitos civis.

Neste sentido, Cappelletti (1982, p. 774) tratava do tema:

A legislação especial é o instrumento dessa profunda alteração, avalizada pela Constituição de República. O Código Civil preocupava-se em garantir as regras do jogo (a estabilidade 
das normas); já as leis especiais as alteram sem cerimônia, para garantir objetivos sociais e econômicos definidos pelos Estado. O Poder Público persegue certas metas, desenvolve nesta direção programas assistenciais, intervém conspicuamente na economia, vale-se de dirigismo contratual acentuado. $\mathrm{O}$ legislador trabalha freneticamente para atender à demanda setorial crescente, fala-se mesmo em uma "orgia legiferante".

O Código Civil de 2002 também protege esse direito, espelhando o que já havia sido exposto na Constituição e serão analisados mais adiante. Esta capacidade de governar-se pelos seus próprios meios se deve, principalmente, ao progresso das comunicações. Os acontecimentos e divulgação da imagem na sociedade contemporânea têm alcance cada vez maior graças às mídias impressas e, essencialmente, a internet. A exposição da imagem de pessoas comuns e de pessoas públicas como políticos e artistas tem hoje um alcance difícil de se lidar, devido ao uso das redes sociais. Carlos Roberto Gonçalves (2015, p.188) trata o assunto:

Cabe ao lesado, direito à indenização por dano material ou moral decorrente da violação da intimidade, da vida privada, da honra, e da imagem das pessoas. Nos termos do artigo 20 do Código Civil, a reprodução da imagem para fins comerciais, sem autorização do lesado, enseja direito à indenização, ainda que não lhe tenha atingido a honra, a boa fama ou a respeitabilidade.

Com outro ponto de vista Edilsom Pereira de Farias (2000, p. 162163), entende o direito de imagem como "a exclusão do conhecimento daquilo que se refere somente ao indivíduo em sua esfera íntima".

Conhecido por De Cupis como "direito ao resguardo", dando a clareza de resguardar a imagem do titular do uso indevido ou não autorizado. Comparando com as décadas passadas, nos dias atuais a velocidade com que a informação chega até nós, é muito violenta (muito assustadora). Ocorre que as empresas comerciais, com vistas a explorar este mercado abundante (grande quantidade) de informação e comercializar os seus produtos ou serviços, buscam, a cada dia que passa, um diferencial de destaque, uma identidade visual que a identifique na mídia. 


\subsection{Conceito de Direito de Imagem}

O direito de imagem, consagrado e protegido pela Constituição Federal da República de 1988 e pelo Código Civil Nacional de 2002 como um "direito de personalidade autônomo", se trata da projeção da personalidade física da pessoa, incluindo os traços fisionômicos, o corpo, atitudes, gestos, sorrisos, indumentárias, dentre outros. Alguns juristas ainda distinguem, como direito de imagem, a personalidade moral do indivíduo, o que incluiria traços como a aura, fama, reputação, dentre outros.

$\mathrm{O}$ direito à imagem é relativamente novo no ordenamento jurídico nacional e com as grandes dimensões dos meios de comunicação, tem se tornado cada vez mais importante determinar qual a possibilidade de utilização da imagem das pessoas nos vários meios em que vivem. $\mathrm{O}$ direito de imagem, tem como base as propagandas e publicidades nas quais são expressadas pelas mídias, muitas vezes para a venda de produtos ou o fortalecimento de uma marca, utilizandose da imagem de pessoas famosas que possam dar maior credibilidade aos mesmos. Existe um enorme crescimento e divulgação dentro dos meios de comunicação, o direito à imagem vem em um alto destaque no relacionamento social existente.

Como relata em um trecho de sua obra, Carlos Alberto Bittar (2015, p. 209), define que o direito à imagem de um indivíduo: "Consiste no direito que a pessoa tem sobre a sua forma plástica e respectivos componentes distintos (rosto, olhos, perfil, busto) que a individualizam no seio da coletividade".

Ou seja, esse direito compreende as características que identificam como um indivíduo sobressai em meio a coletividade e a sociedade. Devido a essas características que se pode notar que o direito a imagem necessita de um cuidado maior do que outros direitos sobre a pessoa humana, pois os danos causados à imagem de outrem podem ser até mesmo solucionados. As partes firmam um acordo utilizando-se um 
contrato civil, cujo valor pago deve ser em uma forma harmônica com a exposição do jogador pelo clube. Como esse contrato não é constatado pela legislação trabalhista, o valor devido tem uma carga tributária muito menor ao clube e ao próprio atleta.

\subsection{A Proteção do Direito à Imagem}

É essencial ter uma proteção, na qual o ordenamento jurídico foca, a defesa dos direitos de personalidade, no que se refere principalmente ao respeito à dignidade da pessoa humana, como por exemplo, conseguir a reparação de danos materiais e morais e o direito de indenização decorrente dessa violação. Os direitos que são inerentes e inalienáveis, visam à defesa de valores inatos ao cidadão, o novo Código Civil e a Constituição Federal vieram para defender e assegurar a concreção destes direitos concernentes à pessoa humana, por meio de medidas judiciais adequadas que devem ser registradas pelo ofendido ou pelo lesado, a fim de protegê-lo. A proteção a imagem da pessoa física e jurídica, ela está expressamente escrita no art. $5^{\circ}$, inciso $\mathrm{X}$ da Constituição da República no qual menciona: "São invioláveis a intimidade, a vida privada, a honra e a imagem das pessoas, assegurado o direito a indenização pelo dano material ou moral decorrente de sua violação".

Como descrito acima, a proteção em que a Constituição da República alega, é a indenização pelo dano material ou moral decorrente ao acontecimento. Luís Roberto Barroso (2004. p. 273) defende a tese que o direito à imagem protege a honra da pessoa humana, como descrito abaixo:

$\mathrm{O}$ direito à imagem protege a representação física do corpo humano ou de qualquer de suas partes, ou ainda de traços característicos da pessoa pelos quais ela possa ser reconhecida. A reprodução da imagem depende, em regra, de autorização do titular. Nesse sentido, a imagem é objeto de um direito autônomo, embora sua violação venha 
associada, com frequência, à de outros direitos da personalidade, sobretudo a honra.

Tendo como proteção desse direito a Constituição da República Federativa do Brasil de 1988 e também pelo Código Civil de 2002

\section{Utilização do Contrato da Licença de Uso de Imagem a ser explorada por Pessoa Jurídica}

A licença ao uso da imagem reveste-se de nítida natureza contratual, o que se pretende, neste momento, é analisar a conexão daquele com o contrato de trabalho do esportista profissional de futebol.

Em primeiro lugar, vale observar que os contratos podem ser classificados como principais e acessórios. Aqueles são os que têm existência própria, autônoma e não dependem de qualquer outro. $\mathrm{O}$ segundo são os contratos que dependem de outro para a sua existência, como a cláusula penal, a fiança e dentre outros. Nas lições de Carlos Roberto Gonçalves (2004, p. 82), a distinção entre estes contratos encontra justificativa no princípio geral de que o acessório segue o principal. Nesse passo, a consequência da aplicação deste princípio geral é que nulo o contrato principal o mesmo ocorrerá com o acessório, mas a recíproca não é verdadeira. Muitos são os casos em que a PJ "Pessoa Jurídica", firmam contratos de uma forma sagaz, aumentando as parcelas relativas no uso de imagem.

A C.L.T - Consolidação das Leis do Trabalho, em seu artigo $9^{\circ}$, dispõe que "ao contrato de trabalho com regime especial aplicamse as regras gerais deste Código que sejam compatíveis com a sua especificidade". Neste raciocínio, observa-se que os produtos ou serviços na qual se utiliza a imagem, demonstram por exemplo, (Personalidades em destaques de artistas; Pessoas que tenham um corpo físico perfeito 'empresas que comercializam produtos de estética e beleza' e Pessoas com credibilidade públicas). 
Encontra-se com isto, que a licença para utilização da imagem é algo que se encontra vinculada a personalidades de destaque ou artistas. A ideia é atingir o público consumidor e, para que isto ocorra, a melhor alternativa é a exposição de uma imagem de destaque já consagrada. $\mathrm{O}$ uso da imagem sem consentimento do titular, como sinaliza os termos da Carta Magna (inciso X, do artigo $5^{\circ}$ ), enseja indenização. Calcados neste fundamento, reportamo-nos a importante aresto jurisprudencial do Tribunal de Justiça do Estado do Rio de Janeiro:

RESPONSABILIDADE CIVIL DE FABRICANTE -
RESPONSABILIDADE CIVIL DE ESTABELECIMENTO
COMERCIAL - USO NÂ AUTORIZADO DE
FOTOGRAFIA PARA FINS PUBLICITÁRIOS - LESÃO DO
DIREITO A IMAGEM - PROVA DA CULPA AQUILIANA
- DESNECESSIDADE - VALOR DA INDENIZAÇÃO -
AÇÃO INDENIZATÓRIA - DIREITO DE IMAGEM - Uso
inconsentido de fotos da autora, em lojas comerciais com o
objetivo de fazer propaganda de produtos óticos fabricados por
uma das rés e vendidos pela outra. Desnecessidade da existência
de lucro ou culpa do fabricante dos produtos e do lojista que os
oferece ao público. Violação do direito de imagem da autora.
Direito a indenização reconhecida. Verba indenizatória arbitrada
em 2.000 salários-mínimos reduzida para 300 salários-mínimos.
(RIO DE JANEIRO, 2000).

Todo contrato civil, expõe, algumas cláusulas, nas quais são: A finalidade; O tempo de duração; $O$ modo de remuneração e as penalidades em caso de descumprimento ou rompimento antecipado.

\subsection{Salário}

"O salário é aquele valor dado pelo empregador para o trabalhador que cumprir com suas obrigações", segundo Amaury Mascaro do Nascimento (1994, p. 106). Assim, o empregador por meio de lei, terá que pagar um salário mínimo no qual é o menor pagamento oferecido a um trabalhador no Brasil. Esse valor, de acordo com a Constituição Federal deverá atentar as diversas necessidades (educação, lazer, transporte, saúde, etc.) de um cidadão e ele é definido por lei. 


\subsection{Conceito}

O conceito de salário refere-se à remuneração atribuída pelo exercício/desempenho das funções em determinado emprego/ trabalho. Sergio Pinto Martins (2017, p. 117) conceitua: "Salário é a prestação fornecida diretamente ao trabalhador pelo empregador em decorrência do contrato de trabalho, seja em razão da contraprestação do trabalho ou outros que a lei indicar".

O salário era um costume entre os romanos que pagavam aos seus empregados domésticos com quantidades de sal. "Posteriormente, foram sendo empregados outros meios de pagamento do salário, como óleo, animais, alimentos, etc." Ainda é possível dizer que salário, na acepção histórica, veio como uma forma de efetivar a transformação do regime escravagista para um regime de liberdade de trabalho, importante ressaltar que esse assunto, está diretamente ligada, às relações de trabalho e de emprego e correspondem, de acordo com a análise feita por Mauricio Godinho Delgado (2013, p. 712) específica "às parcelas contraprestativas pagas ao empregado em função da prestação de serviços ou da simples existência da relação de emprego".

Essa remuneração dependerá do acordo com o que foi definido no contrato de trabalho e, geralmente são estipuladas as remunerações que são representadas pelo salário-base, além das comissões, valetransporte, gratificações e outros benefícios.

\subsection{Natureza Jurídica}

No mundo jurídico atual um salário tem a sua natureza jurídica reconhecida como sendo alimentar. Como observa-se acima, a natureza jurídica é reconhecidamente sendo alimentar, Mozart Victor Russomano (1978, p. 447) ressalta que o salário e a remuneração possuem traços comuns e ambos são essencialmente alimentares, pois se trata da subsistência dos trabalhadores. De forma mais incisiva afirma alega 
"a natureza alimentar do salário reclama, de parte do legislador, regulamentação cuidadosa" (RUSSOMANO, 1978, p. 447).

Não há dúvida de que a natureza do salário é mesmo alimentar. É o salário quem garante a sobrevivência do empregado, até mesmo porque este só trabalha por necessidade de sobreviver.

\section{Tributação de Rendimentos por Meio de Imposto de Renda}

\subsection{Imposto de Renda}

Os impostos são desvinculados de qualquer atuação estatal, decretadas exclusivamente em função do jus imperii do Estado. Seu fato gerador é sempre uma situação independente de qualquer atividade estatal específica, relativa ao contribuinte e o imposto sempre representa uma retirada da parcela de riqueza do particular, respeitada a capacidade contributiva deste.

A doutrina costuma classificar os impostos em diretos e indiretos. "Imposto direto seria aquele em que não há repercussão econômica do encargo tributário, isto é, aquela pessoa que praticou o fato tipificado na lei suporta o respectivo ônus fiscal", orienta Paulo de Barros Carvalho (2002, p. 213).

Assim, parafraseando o autor supracitado, "o imposto indireto seria aquele em que o ônus financeiro do tributo é transferido ao consumidor final, por meio do fenômeno da repercussão econômica." Neste sentido, "o proporcional é aquele que mantém a mesma alíquota, qualquer que seja o valor tributável", assevera Kiyoshi Harada (2011, p. 187). Já "o imposto progressivo é aquele que exige uma alíquota maior à medida que o valor tributável vai aumentando", afirma o mesmo autor.

Quem também conceitua aspectos dos impostos, como a seletividade é Luciano Amaro (2009, p. 389):

A progressividade é aquela em que cada alíquota maior é calculada, tão somente, sobre a parcela do valor compreendida entre o limite inferior e o superior, de sorte a exigir a aplicação 
de tantas alíquotas quantas sejam as parcelas de valor para, serem somados todos os valores parciais, obtendo-se o montante do imposto a pagar.

Já em relação, de modo específico, sobre o fato gerador do imposto de renda, Eduardo Sabbag (2014, p. 216) discorre:

O fato gerador do imposto de renda é a aquisição da disponibilidade econômica ou jurídica de renda (decorrente do capital, do trabalho ou da conjugação de ambos) e de proventos de qualquer natureza, assim entendidos todos os acréscimos não compreendidos no conceito de renda.

No que se refere ao imposto de renda no artigo. 153, III da CF e no artigo. 43 do CTN, Hugo de Brito Machado (2015, p. 320) afirma:

O âmbito material de incidência do imposto de renda é a aquisição da disponibilidade econômica ou jurídica de renda, assim entendido o produto do capital, do trabalho, ou da combinação de ambos, e de proventos de qualquer natureza, assim entendidos os acréscimos patrimoniais não compreendidos no conceito de renda.

O Imposto de Renda, possui 3 (três) incidências: Pessoa Física; Retido na Fonte e Pessoa Jurídica. O Imposto de Renda por Pessoa Física, é aquele que incide sobre a renda e os proventos de contribuintes residentes no país ou residentes no exterior que recebam rendimentos de fontes do Brasil. O Imposto de Renda retido na fonte é uma obrigação tributária principal em que a pessoa jurídica ou equiparada, está obrigada a reter do beneficiário da renda, o imposto correspondente, nos termos estabelecidos pelo Regulamento do Imposto de Renda e por último o Imposto de Renda por Pessoa Jurídica, é um tributo federal pago pelas pessoas jurídicas e empresas individuais domiciliadas no Brasil e que possuam um CNPJ - Cadastro Nacional das Pessoas Jurídicas, ou seja, registradas e operantes. Ele incide sobre a arrecadação das empresas.

\subsection{Imposto de Renda por Pessoa Jurídica}

O fato gerador do Imposto sobre a Renda de Pessoa Jurídica é o lucro, ganho ou acréscimo patrimonial e não a mera realização de 
receita. A base de cálculo do Imposto de Renda de Pessoa Jurídica é determinado de acordo com a lei vigente na data da ocorrência do fato gerador, o lucro real, presumido ou arbitrado, com base no período de apuração. Integram a base, todos os ganhos e rendimentos declarados, independentemente da natureza, espécie ou de alguma existência de título ou contrato escrito, que possuem os mesmos efeitos do previsto incidente do imposto. A alíquota do Imposto de Renda da Pessoa Jurídica é de $15 \%$ nos termos do art. $3^{\circ}$ da Lei $n^{\circ}$ 9.249/95. Para a parcela do lucro que exceder o valor resultante da multiplicação de $\mathrm{R} \$ 20.000,00$ (Vinte Mil Reais) pelo número de meses do respectivo período de apuração aplica-se um adicional de imposto de renda à alíquota de $10 \%$.

Todavia, deve-se apontar que a constituição de uma pessoa jurídica para explorar a atividade de prestação de serviço de sessão de direitos de imagem dá início a incidência do Imposto de Renda Pessoa Jurídica (IRPJ), da Contribuição Sobre o Lucro Líquido (CSLL), da Contribuição para Financiamento da Seguridade Social (CONFINS), do Programa de Integração Social (PIS), e do Programa de Formação do Patrimônio do Servidor Público (PASEP), da Contribuição Previdência Patronal (CPP) e do Imposto Sobre a Prestação de Serviço de Qualquer Natureza (ISS), além de taxas a serem cobradas por órgãos públicos que venham a exercer o exercício regular poder de polícia.

No que diz respeito a COFINS haveria a incidência de uma alíquota de 3\% sobre o faturamento total da empresa e a título de PIS/ PASEP haveria a incidência de uma alíquota de $0,65 \%$ nos termos do artigo $2^{\circ}$, I alínea $\mathrm{B}$, da Lei $\mathrm{n}^{\circ} 10.833 / 03$ e do artigo $2^{\circ}$, $\S 4$, inciso I, da Alínea B, da Lei $\mathrm{n}^{\circ} 10.637 / 02$. No que diz respeito a CPP, a uma incidência de $20 \%$ sobre o total da remuneração pagas ou creditadas, nos termos do artigo $22^{\circ}$ da Lei no $8.212 / 91$, em relação CSLL, observase que a base de cálculo é o lucro aferido pela empresa e a alíquota de $9 \%$ nos termos do artigo $3^{\circ}$ inciso III, da Lei $n^{\circ} 7.689 / 88$. Por fim, no que tange o ISS a base de cálculo será o preço cobrado pela prestação de cessão do direito de imagem e a alíquota será estabelecida pela lei 
municipal que instituíram o tributo não podendo superar 5\%, nos termos dos artigos $7^{\circ}$ e $8^{\circ}$ da Lei Complementar $n^{\circ}$ 116/2003.

Portanto, do ponto de vista econômico, a tributação pela cessão do direito de imagem por pessoa jurídica, em detrimento da tributação pelo IRPF, somente valeria a pena se a soma de tais tributos viesse a corresponder a um valor inferior aquele obtido pela aplicação do percentual correspondente a $27,5 \%$, o qual geralmente é utilizado em se tratando de atletas de futebol, que venham a perceber grandes remunerações.

\subsection{Imposto de Renda Pessoa Jurídica a ser recolhido por meio do Simples Nacional}

O Simples, é uma forma simplificada e englobada de recolhimento de tributos e contribuições, tendo como base de apuração a receita bruta. Sendo instituído pela Lei Complementar Federal no 123/2006. Ressalta-se também que ele é facultativo para as empresas, ou seja, faz parte dele quem quer.

As pessoas jurídicas que se enquadram na condição de microempresa ou empresa de pequeno porte poderão optar pela inscrição no Simples Nacional, recolhendo em guia única diversos tributos. Sendo um regime de arrecadação, cobrança e fiscalização de tributos. Foi criado pela Lei Geral para simplificar a vida do empreendedor de pequeno porte. Ele unifica oitos tributos em um único boleto e reduz sua carga tributária. Atualmente, a divisão, levando em conta a receita total da empresa nos últimos meses, ocorre da seguinte forma: a) Microempreendedor Individual: até R \$ 81.000,00 (Oitenta e Um Mil Reais); b) Micro e Pequenas Empresas: até R\$ 360.000,00 (Trezentos e Sessenta Mil Reais); e, c) Empresa de Pequeno Porte: até R\$ 3.600.000,00 (Três Milhões e Seiscentos Mil Reais).

Já o Microempreendedor Individual (MEI) é regulamentado pela Lei Geral, mas não é classificado como MPE. Outro detalhe do 
Simples Nacional, é que as alíquotas são progressivas, podendo ser, nas faixas superiores de receita, especialmente para empresas de serviços, mais onerosas para do que os regimes de Lucro Real ou Presumido.

Assim, deve-se apontar que a constituição de uma pessoa jurídica para explorar a atividade de prestação de serviço de cessão de direitos de imagem havendo a opção pelo simples, implicará na substituição da incidência do Imposto de Renda Pessoa Jurídica (IRPJ), da Contribuição Sobre o Lucro Líquido (CSLL), da Contribuição para Financiamento da Seguridade Social (CONFINS), do Programa de Integração Social (PIS), do Programa de Formação do Patrimônio do Servidor Público (PASEP), da Contribuição Previdência Patronal (CPP) e do Imposto Sobre a Prestação de Serviço de Qualquer Natureza (ISS).

Destarte, se o prestador de serviço de cessão de direito de imagem puder se enquadrar no simples deverá, por força do Artigo 18, $\S 5^{\circ}$ - I, inciso XII sujeitar-se à tabela do anexo V. Em tal situação o máximo que pagará a título de Imposto de Renda da Pessoa Jurídica, tendo obtido um faturamento bruto $\mathrm{R} \$ 3.600 .000,00$ nos últimos doze meses, com média de $\mathrm{R} \$ 300.00,00$ por mês por meio do simples, o correspondente a $5,25 \%$ de seu faturamento mensal. Todavia, ao todo a título do simples, poderá ter incidente sobre seu faturamento mensal uma alíquota de até $15,50 \%$ a título do simples, menor, assim, que a maior alíquota de tributação do IRPF, 27,50\%.

Portanto, na maior tributação possível a título do simples, mesmo que a criação da Pessoa Jurídica, implique na substituição de outros tributos não incidente sobre pessoas físicas (CSLL, PIS/PASEP, COFINS, CPP, ISS), a tributação a título de rendimentos mensais seria de $12 \%$ menor que a tributação sobre o salário de uma pessoa física que correspondesse a uma média de $\mathrm{R} \$ 300.000,00$ mensais. 


\subsection{Imposto de Renda por Pessoa Física}

A ocorrência do fato gerador, tem como objeto o pagamento de tributo ou penalidade pecuniária e extingue-se juntamente com o crédito dela. É necessariamente sobre a situação da ocorrência do fato gerador do imposto de renda, segundo o disposto no art. $n^{\circ} 43$ do CTN, é a aquisição da disponibilidade econômica ou jurídica de renda, assim o produto do capital, do trabalho ou da combinação de ambos, ou de proventos de qualquer natureza, constituídos pelos acréscimos patrimoniais não compreendidos no conceito de renda.

O Imposto de Renda, todo ano deve ser declarados pelos Brasileiros, sendo elaborado um relatório, na qual será conferido se todos os impostos foram devidamente pagos. Caso o indivíduo contribui com um valor acima do esperado, é realizado uma devolução, conhecida como restituição. Sendo assim, o contribuinte efetuando o pagamento a mais, será preciso que informe a numeração da sua conta bancária para que o dinheiro seja restituído. Como visto o fato gerador previsto na pessoa física, o Código Tributário Nacional, artigos $n^{\circ} 43$ e $\mathrm{n}^{\circ} 144$, parágrafo $2^{\circ}$, demonstra exceções à regra geral do fato gerador, ao dispor que a lei:

a) estabelecerá as condições e o momento em que se dará a disponibilidade para fins de incidência do imposto de renda relativamente à receita ou rendimento oriundos do exterior; e b) fixará expressamente a data em que o fato gerador se considera ocorrido nas hipóteses de impostos lançados por períodos certos de tempo.

A base de cálculo é bem simples de entender, ela é calculada em cima do montante de rendas, ou até mesmo de proventos tributáveis. Alíquotas, são consideradas progressivas e variáveis da pessoa física. Pela tabela em vigor e que não é corrigida desde 2015, estão isentos da "mordida" mensal na folha de pagamento apenas aqueles que recebem até $\mathrm{R} \$ 1.903,98$ por mês, descontada a contribuição previdenciária. A partir deste valor, as retenções são calculadas com base em alíquotas de 
$7,5 \%, 15 \%, 22,5 \%$ ou $27,5 \%$ sobre o valor dos rendimentos, descontada a parcela dedutível (desconto fixo) para cada faixa de rendimento.

Por fim, deve-se ressaltar que no caso de atleta profissional, havendo a incidência do imposto de renda o mesmo deverá ser retido na fonte pelo clube empregador e repassado a receita federal.

\section{Da Desconsideração de Ato ou Negócios Jurídicos Praticados com a Finalidade de Dissimular a Ocorrência de Fato Gerador ao Tributo}

Sobre a possibilidade de a autoridade administrativa desconsiderar instrumentos particulares, utilizados para práticas de sonegação, assim dispõe o Código Tributário Nacional:

Art. 116. Salvo disposição de lei em contrário, considera-se ocorrido o fato gerador e existentes os seus efeitos:

$[\ldots]$

Parágrafo único. A autoridade administrativa poderá desconsiderar atos ou negócios jurídicos praticados com a finalidade de dissimular a ocorrência do fato gerador do tributo ou a natureza dos elementos constitutivos da obrigação tributária, observados os procedimentos a serem estabelecidos em lei ordinária. (Incluído pela Lcp nº 104, de 10.1.2001).

Portanto, é necessário analisar de qual forma a "autoridade administrativa" poderá sancionar o agente do "negócio jurídico praticado com a finalidade de dissimular a ocorrência do fato gerador", bem como a aplicação e o entendimento prático de cada uma das formas (simulação, fraude à lei, abuso de forma e de direito e negócio jurídico indireto) na jurisprudência atual.

É necessário frisar que a inclusão do parágrafo único ao artigo $\mathrm{n}^{\mathrm{o}} 116$ do CTN pelo advento da LCP ${ }^{\circ}$ 104/01 fez-se necessária no sentido de permitir à autoridade tributária desconsiderar atos ou negócios jurídicos praticados com a finalidade de elisão, gerando um instrumento eficaz ao combate de procedimentos tributados praticados de formas "alternativas" à lei. O termo "dissimular", tem o sentido de 
disfarçar, ludibriar ou esconder. $\mathrm{O}$ ato dissimulado é aquele ocultado pela simulação. Há uma ressalva. O parágrafo único do art. $\mathrm{n}^{\circ} 116$ do CTN poderá ser aplicado somente nos casos em que a autoridade fiscal comprovar a existência de condutas que visam afastar a norma jurídica de incidência tributária mediante a simulação relativa, ou seja, aquela em que o negócio aparente oculta o negócio verdadeiro, aquele que dá origem à incidência tributária. Sobre a dissimulação, assim leciona o tributarista Alexandre Naoki Nishioka (2010):

É preciso ficar claro não só o que significa a dissimulação, mas também quais procedimentos a Receita Federal vai adotar para fiscalizar esses casos. Isso trará mais segurança jurídica ao contribuinte, uma certeza maior em relação à interpretação da lei, afirmou o advogado. Ele, que também é membro do Conselho Administrativo de Recursos Fiscais (Carf), tratou do tema na palestra Planejamento Tributário: a regulamentação do parágrafo único do artigo 116 do CTN.

Aonde ele acredita que apenas com a definição do termo será reconhecido o verdadeiro alcance do dispositivo. Assim, se o indivíduo vem a adquirir a propriedade de um imóvel, por meio de um instrumento público ou particular compra e venda, apontando um valor para o negócio menor do que o real, a fim de impor uma base de cálculo menor para fins de pagamento de ITBI, estaria praticando sonegação e não elisão fiscal.

\section{Da Legalidade de Atribuição de Natureza Salarial à Rendimentos Obtidos à Títulos de Direitos de Imagem por Pessoas Jurídicas Constituídas por Atletas Profissionais}

De acordo com as especificações do trabalho do jogador profissional, o seu contrato de trabalho tem uma diferença em relação aos contratos normais de trabalho regidos pela CLT. Uma das controvérsias é que o contrato de trabalho do atleta profissional deve ser sempre ser celebrado por escrito, uma forma normal dentro de suas limitações. O contrato de trabalho do atleta profissional é um instrumento particular de acordo na qual são aplicadas as leis trabalhistas nos empregos com as 
devidas peculiaridades à profissão. Como descreve professor Domingos Sávio Zainaghi (1998, p. 55-56):

[...] sendo contrato de emprego, não há que se falar em prestação de serviços, sendo que as leis trabalhistas são a ele aplicáveis, não por analogia, mas por imperativo de lei e sobretudo do direito, uma vez o caráter protecionista do direito do trabalho.

De acordo com o Conselho Nacional de Desportos, os contratos deverão ser firmados e registrados nos mesmos e inscritos em entidades regionais e na $\mathrm{CBF}$, uma forma de proteção às partes. Como visto, o contrato de trabalho do jogador profissional de futebol é um contrato com muitas especificidades inerentes à atividade exercida pelo atleta. Porém, também se depreende do estudo que a imagem do atleta é amplamente utilizada neste contrato, sendo que muitas vezes pode trazer lucro à entidade desportiva que este representa apenas estampando sua marca.

Um exemplo na qual se pode visualizar é que a maioria dos clubes firmam contratos de uma forma sagaz com os atletas, aumentando as parcelas relativas no uso de imagem, sendo considerado uma estratégia para não divulgarem o verdadeiro salário e também para não ser aplicado tantos tributos. Como visualizado em diversos casos, é muito comum se deparar com a prática realizada pelos clubes de pagar a maior parte da remuneração dos atletas profissionais a título de direito de imagem, e, o menor, por meio de salário.

$\mathrm{O}$ direito de exploração da imagem de atleta profissional tem natureza civil e, portanto, não se confunde com o contrato especial de trabalho. Este tópico, demonstra a criação de uma pessoa jurídica para administração do direito de imagem dos desportistas, considerando a tributação favorecida das pessoas jurídicas em relação às físicas para fins de apuração do Imposto de Renda. Tendo um planejamento tributário, como prática de organização e programação de atos futuros para redução do pagamento de impostos. 
Porém, recentemente, vem sendo noticiado pela imprensa brasileira que a receita federal vem desconsiderando contratos de cessão de direitos de imagens, celebrados entre clubes e pessoas jurídicas criadas por atletas profissionais. Há notícias de autuação de mais de cento e cinquenta atletas. Entretanto, tais autuações estão sendo praticadas de modo contrário as disposições da Lei $n^{\circ}$ 9.615/98 e do Código Civil. De acordo com Artigo no ${ }^{\circ}$ 87-A da Lei no 9.615 de 24 de março de 1998, menciona:

O direito ao uso da imagem do atleta pode ser por ele cedido ou explorado, mediante ajuste contratual de natureza civil e com fixação de direitos, deveres e condições inconfundíveis com o contrato especial de trabalho desportivo. (Incluído pela Lei ${ }^{\circ}$ 12.395, de 2011). Parágrafo único. Quando houver, por parte do atleta, a cessão de direitos ao uso de sua imagem para a entidade de prática desportiva detentora do contrato especial de trabalho desportivo, o valor correspondente ao uso da imagem não poderá ultrapassar $40 \%$ (quarenta por cento) da remuneração total paga ao atleta, composta pela soma do salário e dos valores pagos pelo direito ao uso da imagem. (Incluído pela Lei $\mathrm{n}^{\circ}$ 13.155, de 2015).

Observa-se, portanto, que há clara previsão legal autorizando a exploração de direito de imagem pelos atletas profissionais. Mediante assim, é totalmente lícita a criação de pessoa jurídicas por atletas profissionais que venham a explorar os direitos de imagem de seus constituintes mediante ajustes contratuais de natureza cível. Além disso o Artigo $\mathrm{n}^{\circ} 980-\mathrm{A}, \S 5^{\circ}$, do Código Civil aponta a forma pela qual a cessão de direito de imagem de atletas profissionais deve ocorrer:

Art. 980-A. A empresa individual de responsabilidade limitada será constituída por uma única pessoa titular da totalidade do capital social, devidamente integralizado, que não será inferior a 100 (cem) vezes o maior salário-mínimo vigente no País.

$[\ldots]$

$\S 5^{\circ}$ Poderá ser atribuída à empresa individual de responsabilidade limitada constituída para a prestação de serviços de qualquer natureza a remuneração decorrente da cessão de direitos patrimoniais de autor ou de imagem, nome, marca ou voz de que seja detentor o titular da pessoa jurídica, vinculados à atividade profissional. 
Observa-se a clara e nítida autorização legal para exploração, na forma de empresas individuais de responsabilidade limitada, da cessão dos direitos de imagem do atleta profissional titular da pessoa jurídica. Há, assim, clara declaração do código civil de natureza de direito disponível aos direitos de imagem, podendo estes serem sujeitos a exploração econômica.

Todavia, a que se observar a limitação prevista pelo $\S$ único, do Artigo $n^{\circ} 87-A$, da Lei ${ }^{\circ} 9.615 / 98$, que veta o pagamento de valor correspondente ao uso de direito de imagem em valor superior a $40 \%$ da remuneração total paga ao atleta.

\section{Considerações finais}

O que se verifica é que vários atletas profissionais de futebol criam pessoas jurídicas para administrarem a exploração da própria imagem. Assim, são firmados contratos entre duas pessoas jurídicas, o primeiro que deseja explorar comercialmente a imagem de uma celebridade e a segunda criada por esta.

Muitas vezes, o titular da imagem adquiri uma empresa jurídica que promoverá a divulgação e cessão, através desses contratos de licença de uso. Sendo assim, como o pagamento ocorrerá para uma pessoa jurídica, não tem que mencionar o Imposto de Renda Retido na Fonte. Se analisarmos a tabela do IRRF tem alíquota máxima de 27,5\%, chegando à conclusão que, para o titular da imagem, houve uma imensa economia fiscal.

A quantia paga a título de licença de uso de imagem não é isenta de tributos. Porém, de modo algum, a referida quantia sofre a mesma tributação daquela compelida ao salário.

Os contratos de trabalho firmados com os atletas profissionais, ainda pouco lembrado pela doutrina brasileira, vem ganhando certa repercussão devido ao alcance social do esporte e da mídia esportiva. 
Indiscutível que o futebol desperta um enorme interesse na sociedade, atingindo todos os estilos sociais, raças, crenças, etc.

Conclui-se que diante do Art. $n^{\circ}$ 87-A da Lei Pelé, do Art. $n^{\circ}$ 980-A do CC/2002, há autorização legal para a exploração de direito por empresa de responsabilidade individual cuja a titularidade pertença a atleta profissional. Apontar que, como demonstrado, a carga tributária incidente em tal atividade será menor que do aquele incidente sobre salário pago ao atleta como pessoa jurídica.

\section{Referências}

AMARO, Luciano. Direito Tributário Brasileiro. 15. ed. São Paulo: Saraiva, 2009.

CAPPELLETTI, Mauro. Riflessioni sulla creatività della giurisprudenza nel tempo presente. Rivista Trimestrale di Diritto e Procedura Civile, Milano, v. 36, n. 3, p. 774-792, 1982.

CARVAlHO, Paulo de Barros. Curso de Direito Tributário. 13. ed. São Paulo: Saraiva, 2000.

BARROSO, Luís Roberto. Colisão entre liberdade de expressão e direitos da personalidade: critérios de ponderação: interpretação constitucionalmente adequada do código civil e da lei de imprensa. Revista de Direito Administrativo, n. 235, jan./mar. 2004. Disponível em: http://ambitojuridico.com.br/site/?n_link=revista_artigos leitura\&artigo_id $=17579 \&$ revista_caderno $=9$. Acesso em: $23 \mathrm{fev}$. 2016.

DELGADO, Mauricio Godinho. Curso de Direito do Trabalho. 12 ed. São Paulo: LTr, 2013.

DINIZ, Maria Helena. Curso de direito civil. 16. ed. São Paulo: Saraiva, 2002, v. I.

FARIAS, Edilsom Pereira de. Colisão de Direitos: a honra, a intimidade, a vida privada e a imagem versus a liberdade de expressão e informação. Porto Alegre: Sergio Antônio Fabris Editor, 2000. 
FRANÇA, Rubens Limongi. Instituições de direito civil. São Paulo: Saraiva, 1988.

GOMES, Orlando. Introdução no Direito Civil. Rio de Janeiro: Forense, 2007.

GONÇALVES, Carlos Roberto. Direito Civil Brasileiro: Parte Geral. 7. ed. São Paulo: Saraiva, 2015, v. I.

GONÇALVES, Carlos Roberto. Direito Civil Brasileiro: Parte Geral. 7. ed. São Paulo: Saraiva, 2015, v. I.

GONÇALVES, Carlos Roberto. Direito Civil Brasileiro: contratos e atos unilaterais. São Paulo: Saraiva, 2004.

HARADA, Kiyoshi. Direito Financeiro e Tributário. 20. ed. São Paulo: Atlas. 2011.

MACHADO, Hugo Brito. Curso de Direito Tributário. São Paulo: Malheiros Editores, 2015.

MARTINS, Sergio Pinto. Manual de Direito do Trabalho. 10. ed. São Paulo: Saraiva. 2017.

MIRANDA, Francisco Cavalcanti Pontes de. Tratado de direito privado. Atual por. Vilson Rodrigues Alves. 2. ed. Campinas: Bookseller, 2000. Tomo I.

NASCIMENTO, Amauri Mascaro. Teoria Jurídica do salário. São Paulo: LTr, 1994.

NISHIOKA, Alexandre Naoki. Comentário a respeito do Artigo 116 do Código Tributário Nacional. Disponível em: https://www.conjur. com.br/2010-nov-01/regulamentacao-norma-antielisiva-poe-fimduvida-dissimulacao. Acesso em: 14 abr. 2018.

RUSSOMANO, Mozart Victor. O Empregado e o Empregador no Direito Brasileiro. 6 ed. São Paulo: LTr. 1978.

SABBAG, Eduardo. Manual de Direito Tributário. 6. ed. São Paulo: Saraiva, 2014.

SIQUEIRA, Dirceu Pereira; NUNES, Danilo Henrique. As "moral clauses" como instrumento de cidadania nas relações jurídicas 
contratuais empresariais. Revista de Direito Empresarial - RDEmp, Belo Horizonte, ano 15, n. 1, p. 195-211, jan./abr.2018.

ZAINAGHI, Domingos Sávio. Os atletas profissionais de futebol no direito do trabalho. São Paulo: LTr, 1998. 